\title{
Alpha7 nAChR Expression Is Correlated with Arthritis Development and Inhibited by Sinomenine in Adjuvant-Induced Arthritic Rats
}

\author{
Chong Peng $\mathbb{D}^{1,2}$ Qing-ping Shi, ${ }^{1}$ Jia-yan Liu, ${ }^{1}$ Yan-jun Lv, \\ Jing Li $\mathbb{D}^{1},{ }^{1}$ Lang Yi, ${ }^{1}$ Sha-sha Bai, ${ }^{1}$ Liang Liu, ${ }^{3}$ Pei-xun Wang, \\ Hua Zhou $\mathbb{D},{ }^{3,4}$ Ke-er Huang $\mathbb{D}{ }^{2}$, and Yan Dong $\mathbb{D}^{1}$ \\ ${ }^{1}$ Department of Immunology, Institute of Clinical Pharmacology, Guangzhou University of Chinese Medicine, Guangzhou, China \\ ${ }^{2}$ The First Clinical Medical School, Guangzhou University of Chinese Medicine, Guangzhou, China \\ ${ }^{3}$ Faculty of Chinese Medicine and State Key Laboratory of Quality Research in Chinese Medicine, \\ Macau University of Science and Technology, Avenida Wai Long, Taipa, Macau \\ ${ }^{4}$ International Institute of Translation Chinese Medicine, Guangzhou University of Chinese Medicine, Guangzhou, China
}

Correspondence should be addressed to Hua Zhou; hzhou@must.edu.mo and Yan Dong; dondy001@gzucm.edu.cn

Received 12 January 2019; Accepted 8 April 2019; Published 2 May 2019

Academic Editor: Francisco Solano

Copyright (c) 2019 Chong Peng et al. This is an open access article distributed under the Creative Commons Attribution License, which permits unrestricted use, distribution, and reproduction in any medium, provided the original work is properly cited.

\begin{abstract}
Sinomenine (SIN) is the active ingredient of the Chinese herb Sinomenium acutum that has been used to treat rheumatoid arthritis (RA) for about 30 years in China. Marked expression of the alpha7 nicotinic acetylcholine receptor $(\alpha 7 \mathrm{nAChR})$ in the joint synovium of RA patients suggested a relationship between $\alpha 7 \mathrm{nAChR}$ and RA. This study investigated the relationship between $\alpha 7 \mathrm{nAChR}$ and RA development and the effects of SIN on $\alpha 7 \mathrm{nAChR}$ expression in vivo and in vitro. Sprague-Dawley rats were injected with complete Freund's adjuvant to induce arthritis and then treated with SIN or methotrexate (MTX) from day 0 to day 30. Four clinical parameters-paw volume, arthritic index (AI), serum TNF- $\alpha$ concentration, and erythrocyte sedimentation rate (ESR) - were measured. Splenic lymphocytes were isolated for Bacille Calmette Guerin (BCG) stimulation. $\alpha 7 \mathrm{nAChR}$ expression in tissues and cells was examined by RT-PCR, western blot, immunofluorescence, flow cytometry, and immunohistochemistry. Cell proliferation was evaluated by the CCK- 8 assay. The relationship between $\alpha 7 \mathrm{nAChR}$ expression and the four clinical parameters was analyzed by single-factor correlation analysis. Our results showed that the paw volume, AI, TNF- $\alpha$ concentration, and ESR in adjuvant-induced arthritic (AIA) rats were reduced by SIN or MTX treatment. SIN decreased $\alpha 7 \mathrm{nAChR}$ expression in tissues and cells compared to the model group, while MTX had no significant effect on $\alpha 7 \mathrm{nAChR}$ expression. Moreover, there was a positive relationship between $\alpha 7 \mathrm{nAChR}$ expression and paw swelling, AI, and TNF- $\alpha$ concentration. Splenic lymphocyte activation was accompanied by increased $\alpha 7 \mathrm{nAChR}$ expression, while SIN treatment inhibited cell activation and downregulated $\alpha 7 \mathrm{nAChR}$ expression. $\alpha 7 \mathrm{nAChR}$ expression showed a positive correlation with the progression of RA in AIA rats that may involve lymphocyte activation. Different from MTX, the inhibition of SIN on $\alpha 7 \mathrm{nAChR}$ expression might contribute to its antiarthritic effect, suggesting that SIN could be an important supplement to the treatment strategy for RA.
\end{abstract}

\section{Introduction}

Rheumatoid arthritis (RA) is a systemic inflammatory disease that affects $0.5-1.0 \%$ of the world population. RA is characterized by joint swelling, synovial inflammation, persistent synovial hyperplasia, cartilage and bone damage, and general disability. The severity and progression of RA are affected by susceptibility genes, environmental damage, epigenetic modifications, and posttranslational modifications $[1,2]$. Recent studies found marked expression of the alpha7 nicotinic acetylcholine receptor $(\alpha 7 \mathrm{nAChR})$ in the synovial membranes of RA patients and RA fibroblast-like synoviocytes [3, 4]. $\alpha 7 \mathrm{nAChR}$ is an important receptor in the cholinergic antiinflammatory pathway (CAP) [5]. Treatment with $\alpha 7 \mathrm{nAChR}$ 
agonists decreases proinflammatory factors level in experimental sepsis [6], neuroinflammation [7] and arthritis [5]. It was reported that a lack of $\alpha 7 \mathrm{nAChR}$ increased the severity of collagen-induced arthritis (CIA) in $\alpha 7 \mathrm{nAChR}^{-/-}$mice [8]. On the other hand, another study found that a lack of $\alpha 7 \mathrm{nAChR}$ inhibited development of arthritis [9]. At present, the role of $\alpha 7 \mathrm{nAChR}$ in the progression of $\mathrm{RA}$ remains unclear.

Sinomenine (SIN; 7,8-didehydro-4-hydroxy-3,7-dimethoxy-17-methylmorphinane-6-one, C19H23NO4) is an active alkaloid derived from Sinomenium acutum (Family Menispermaceae), a Chinese herb used extensively in RA treatment in China $[10,11]$. In a previous study, we demonstrated that lipopolysaccharide (LPS) stimulation elevated $\alpha 7 \mathrm{nAChR}$ expression in macrophages, while SIN inhibited the inflammatory response and decreased $\alpha 7 \mathrm{nAChR}$ expression [12].

In the present study, $\alpha 7 \mathrm{nAChR}$ expression during different stages of RA was observed in an arthritis rat model to investigate the correlation between $\alpha 7 \mathrm{nAChR}$ and the clinical progression of RA. In addition, the effects of SIN and methotrexate (MTX) on $\alpha 7 \mathrm{nAChR}$ expression in vivo and in vitro were analyzed.

\section{Materials and Methods}

2.1. Animals. Male Sprague-Dawley rats (100-120 g) were housed in a climate-controlled environment $\left(22-26^{\circ} \mathrm{C}\right.$ at 40 $70 \%$ humidity) with a 12 -h light/dark cycle and given food and drink ad libitum. The animals were adapted to the housing conditions for 7 days prior to the experiments. All experiments were conducted in accordance with the National Institutes of Health guidelines approved by the Ethical Committee for Animal Experiments of Guangzhou University of Chinese Medicine. The rats were anesthetized with 3\% sodium pentobarbital $(1 \mathrm{~mL} / \mathrm{kg})$ and abdominal aortic blood was collected. Subsequently, the rats were sacrificed due to excessive blood loss.

2.2. Reagents and Drugs. Mineral oil was purchased from Bio-Rad (California, USA), SIN was purchased from Melonepharma (Dalian, China), and MTX was purchased from SPH Sine Pharmaceutical Laboratories Co., Ltd (Shanghai, China). M. Tuberculosis Des. H37 Ra and the ELISA kit for measuring TNF- $\alpha$ concentration were purchased from BD Biosciences (San Diego, California, USA). The monoclonal antibody against $\alpha 7 \mathrm{nAChR}$ was purchased from Santa Cruz Biotechnology (Santa Cruz, California, USA), CHRNA7 rabbit polyclonal antibody was purchased from Proteintech (Chicago, USA), and DyLightTM488 fluorescence secondary antibody was purchased from eBioscience (California, USA). Bacille Calmette Guerin (BCG), a vaccine isolated from Mycobacterium bovis, was purchased from Chengdu Institute of Biological Products Co., Ltd (Sichuan, China).

2.3. Adjuvant-Induced Arthritis (AIA) Induction and Treatment. Complete Freund's adjuvant (CFA) was prepared according to established methods [13]. Rats were induced on day 0 by an injection of $0.1 \mathrm{~mL}$ of CFA $(2.5 \mathrm{mg} / \mathrm{mL})$ at the base of the tail through an intradermal route. After the CFA injection, AIA rats $(n=8)$ were treated with SIN (120 $\mathrm{mg} / \mathrm{kg} / \mathrm{d}), \operatorname{MTX}(7.8 \mathrm{mg} / \mathrm{kg} / \mathrm{w})$, or vehicle (PBS) orally from day 0 to day 30 .

2.4. Clinical Evaluation of AIA Rats. Disease progression and severity were evaluated by measuring the arthritic index (AI) and paw volume of both hind paws on days $0,6,12,18,24$, and 30 after CFA injection. There were 8 rats in each group at each time point. According to the degree of swelling and erythema around the paws, the paws were graded from 0 to 4; 16 was the maximum AI score for each animal [14]. The hind paw volume was measured in a volumetric chamber and represented as an average volume of both hind paws.

2.5. Pathology. On day 30 after CFA injection, the rats were sacrificed and the synovia removed. Specimens were fixed for $12 \mathrm{~h}$ in $4 \%$ paraformaldehyde, embedded in paraffin, cut into $4-\mu \mathrm{m}$ sections, and stained with hematoxylin and eosin $(\mathrm{H} \& \mathrm{E})$.

2.6. Measurement of Proinflammation Cytokine Levels. Blood was collected, left at room temperature for $1 \mathrm{~h}$, and then centrifuged at $3000 \mathrm{rpm}$ for $10 \mathrm{~min}$. The supernatant was collected, and TNF- $\alpha$ concentration was measured using a commercially available ELISA kit according to the manufacturer's instructions (BD Biosciences, San Diego, California, USA).

2.7. Measurement of Erythrocyte Sedimentation Rate(ESR). Blood $(120 \mu \mathrm{L})$ was mixed with sodium citrate $(30 \mu \mathrm{L} ; 0.109$ $\mathrm{mol} / \mathrm{L}$ ) and transferred into a $1.0-\mathrm{mm} \times 100-\mathrm{mm}$ capillary (VWR International, West Chester, Pa., USA). The capillary was maintained at an angle of $45^{\circ}$ for $15 \mathrm{~min}$, and then the amount (in millimeters) of clear fluid present at the top portion of the capillary was recorded.

2.8. Immunofluorescence. Peritoneal macrophages were collected on day 30 after CFA injection [15], seeded in a 6-well plate $\left(2 \times 10^{5}\right.$ cell/mL, $1 \mathrm{~mL}$ per well $)$ and cultured for $4 \mathrm{~h}$. Then the cells were washed, fixed in $4 \%$ paraformaldehyde, and washed again. Cells were treated with $1 \%$ Triton X-100 and washed. Nonspecific binding was blocked by $5 \%$ rabbit serum before the cells were incubated with the $\alpha 7 \mathrm{nAChR}(1: 200)$ antibody. Next, cells were incubated with the fluorescence secondary antibody in the dark. Finally, the cells were stained with DAPI and observed under the fluorescent microscope.

2.9. RT-PCR. Total mRNA was extracted from tissues and cells to obtain cDNA according to the manufacturer's protocol. The primers used and the product sizes were: $\alpha 7 \mathrm{nAChR}$ (sense $5^{\prime}$ - GGCCCGGAGAGGACAIAGG-3' ${ }^{\prime}$; antisense $5^{\prime}$-CGGCCACATACGACCCCAGAGT-3'; product size $187 \mathrm{bp}$ ), IFN- $\gamma$ (sense $5^{\prime}$-ATCTGGAGGAACTGGCAAAAGGACG-3'; antisense $5^{\prime}$-CCTTAGGCTAGATTCTGGTGACAGC-3' ${ }^{\prime}$; product size $288 \mathrm{bp}$ ), IL-4 (sense $5^{\prime}$ GTTCTGCTTTCTCATATG-3' ; antisense $5^{\prime}$-AGCGTGGACTCATTCACG-3'; product size $330 \mathrm{bp}$ ), and $\beta$-actin 
(sense $5^{\prime}$-CACCCTGTGCTGCTCACCGAGGCC- $3^{\prime}$; antisense $5^{\prime}$ - CCACACAGATGACTTGCGCTCAGG-3'; product size $720 \mathrm{bp}$ ). The PCR conditions were $95^{\circ} \mathrm{C}$ for $5 \mathrm{~min}$, 40 cycles of $95^{\circ} \mathrm{C}$ for $15 \mathrm{~s}, 60^{\circ} \mathrm{C}$ for $30 \mathrm{~s}$ and $72^{\circ} \mathrm{C}$ for 30 min, and $72^{\circ} \mathrm{C}$ for $5 \mathrm{~min}$. The PCR products were separated by $1.5 \%$ agarose gel electrophoresis and optical density was determined by the UVP gel analysis system (Quantity one, Bio-Rad).

2.10. Immunohistochemistry. Sections were deparaffinized and rehydrated with a series of gradient concentrations of alcohol and endogenous peroxidase activity was blocked with $3 \%$ hydrogen peroxide. Antigen repair was accomplished by microwaving in $0.01 \mathrm{M}$ sodium citrate buffer solution and washing with PBS. Nonspecific binding was blocked with $5 \%$ BSA. Each section was then incubated with $\alpha 7 \mathrm{nAChR}$ antibody (1:200) or PBS, followed by incubation with the anti-mouse HRP secondary antibody. Finally, the sections were treated with a diaminobenzidine substrate-chromogen solution and stained with hematoxylin.

2.11. Western Blot. Protein from tissues or cells was extracted for $\alpha 7 \mathrm{nAChR}$ detection by western blot. For immunoblot analysis, $50 \mu \mathrm{g}$ of protein per lane was fractionated by SDS-PAGE and blotted onto a PVDF membrane (Bio-Rad, USA). The membrane was blocked by a $5 \%$ BSA solution for $2 \mathrm{~h}$ at room temperature, and then incubated with the $\alpha 7$ nAChR antibody (1:200) and a GAPDH antibody (1:1000). After washing with TBST, the membrane was incubated with an anti-mouse IgG antibody $(1: 25,000)$. The membrane was washed with TBST, and bands were detected by the ECL detection method and exposed to X-ray film. The intensity of the bands was subsequently analyzed and quantified by ImageLab software.

2.12. Flow Cytometry. Spleens from control and AIA rats were obtained at day 24 . Splenic lymphocytes were collected and incubated with CD3 $(0.625 \mu \mathrm{L} / \mathrm{T})$ and B220 $(1.25 \mu \mathrm{L} / \mathrm{T})$ antibodies, followed by incubation with the $\alpha 7 \mathrm{nAChR}$ antibody (1:100). Subsequently, the cells were incubated with a secondary goat anti-rabbit fluorescent antibody. Finally, the cells were resuspended in $500 \mu \mathrm{L}$ of PBS and analyzed by flow cytometry.

2.13. Splenic Lymphocyte Assay. Splenic lymphocytes were incubated with SIN $(400 \mu \mathrm{m})$ or MTX $(10 \mu \mathrm{g} / \mathrm{mL})$ in a $96-$ well plate, and 30 minutes later, BCG $(5 \mu \mathrm{g} / \mathrm{mL})$ was added. After $72 \mathrm{~h}$, cell proliferation was evaluated by the CCK8 assay, following the manufacturer's directions.

2.14. Statistical Analysis. Data were evaluated using one-way ANOVA with the Dunnett's multiple comparison post hoc test. Single-factor correlation analyses were used to analyze the relationship between $\alpha 7 \mathrm{nAChR}$ expression and these four clinical parameters: paw volume, AI, serum TNF- $\alpha$ concentration, and ESR. Data were expressed as mean \pm SD and $\mathrm{P}<0.05$ was considered statistically significant. All data were analyzed by the SPSS 17.0 software.

\section{Results}

3.1. SIN Inhibits Clinical Progression in AIA Rats. Inflammatory arthritis is characterized by swelling and erythema in the paws. As shown in Figure 1, there was a significant increase in hind paw volume (Figure 1(a)), AI (Figure 1(b)), ESR (Figure 1(c)), and serum TNF- $\alpha$ concentration (Figure 1(d)) in the model group compared to the control group. Hind paw volume, AI, and TNF- $\alpha$ concentration increased from day 12 to 30 , peaked on day 18 or 24 , and then declined. ESR increased from day 6 to 30, peaked on day 12, and then declined. The above parameters were still higher than the control group on day 30. The clinical progression described above was inhibited by SIN or MTX. The hind paws of the rats were photographed and synovial tissues were isolated for assessment of histopathological changes on day 30 . The model group showed severe soft tissue swelling and paw stiffness in comparison with the control group. In contrast, soft tissue swelling was significantly reduced by SIN or MTX (Figure 1(e)). Furthermore, the lining layer hyperplasia observed in the synovial tissues of the model group, but not the control group, was ameliorated by SIN or MTX (Figure 1(f)).

3.2. SIN Decreases $\alpha 7 n A C h R$ Expression in Tissues and Peritoneal Macrophages of AIA Rats. The expression of $\alpha 7 \mathrm{nAChR}$ in tissues, including the synovium, lung, liver, spleen, thymus, kidney, MLN, and peritoneal macrophages, was analyzed by RT-PCR, immunohistochemistry, immunofluorescence, and western blot. The results (Figures 2 and 3) showed that $\alpha 7 \mathrm{nAChR}$ expression was elevated in the tissues of the model group compared with the control group. Treatment with SIN significantly decreased $\alpha 7 \mathrm{nAChR}$ expression in all tissues evaluated when compared with the model group. In contrast, treatment with MTX did not have significant effects on $\alpha 7 \mathrm{nAChR}$ expression in these tissues.

\section{3. $\alpha 7 n A C h R$ Expression Is Related to Clinical Progression and} Regulated by SIN in AIA Rats. The protein levels of $\alpha 7 \mathrm{nAChR}$ in various tissues were detected on days $0,6,12,18,24$, and 30 by western blot, and the relationship between RA and $\alpha 7 \mathrm{nAChR}$ was determined via a correlation analysis between $\alpha 7 \mathrm{nAChR}$ expression and clinical progression. As shown in Figures $4(\mathrm{a})-4(\mathrm{~g}), \alpha 7 \mathrm{nAChR}$ expression in various tissues increased from day 12 to 30 and peaked on day 18 or 24 in the model group compared to the control group. Treatment with SIN markedly decreased $\alpha 7 \mathrm{nAChR}$ expression from day 12 to 30 compared to the model group, while treatment with MTX had no significant effect on $\alpha 7 \mathrm{nAChR}$ expression. The correlation analysis (Figure 4(h)) showed that hind paw volume and AI were strongly correlated with $\alpha 7 \mathrm{nAChR}$ expression in the synovium, lung, liver, spleen, thymus, kidney, and MLN. Serum TNF- $\alpha$ concentration was strongly correlated with $\alpha 7 \mathrm{nAChR}$ expression in the lung, spleen, thymus, kidney, and MLN, while ESR had no significant correlation with $\alpha 7 \mathrm{nAChR}$ expression in any tissue.

3.4. $\alpha 7 n A C h R$ Expression Is Related to the Activation of Lymphocytes and Regulated by SIN. As shown in Figure 5(a), 


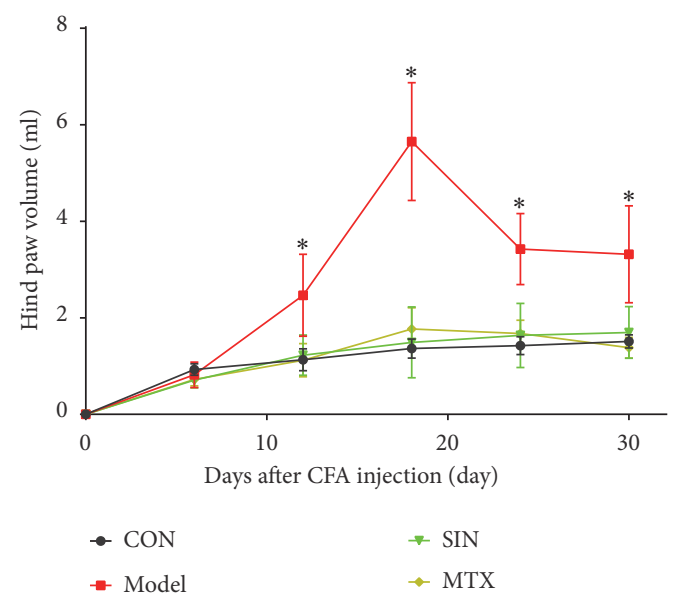

(a)

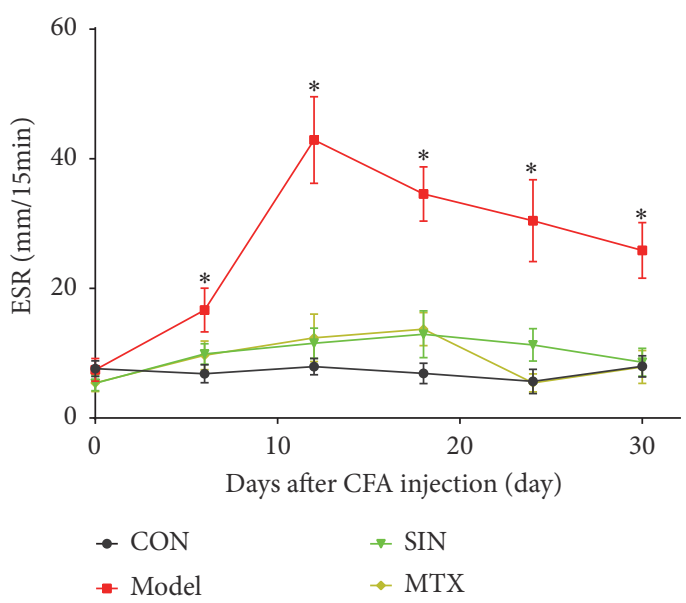

(c)
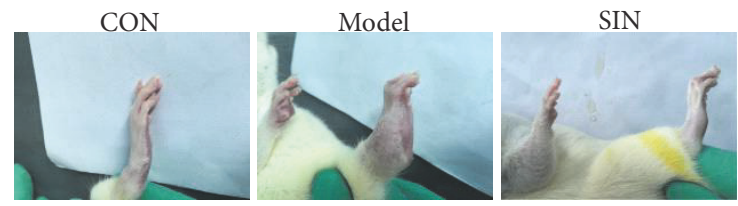

(e)

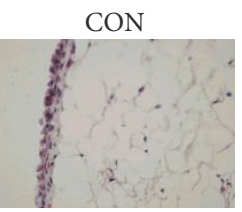
Model

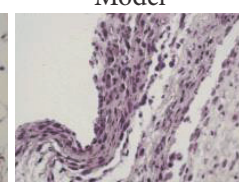

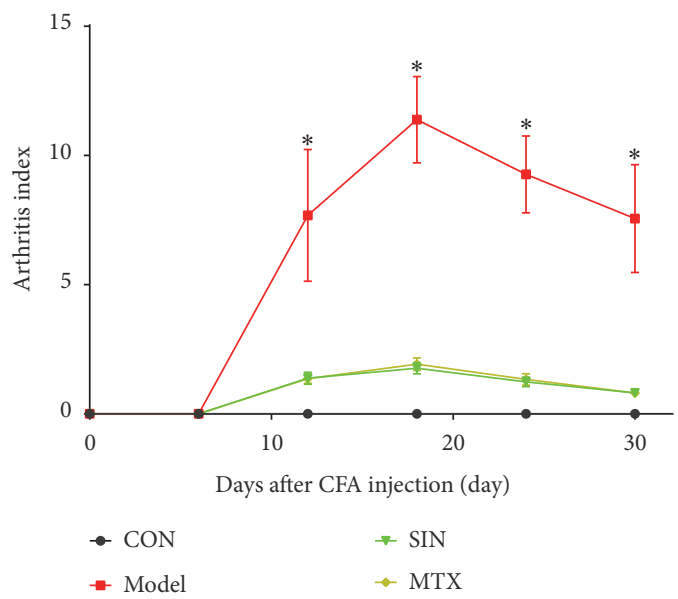

(b)

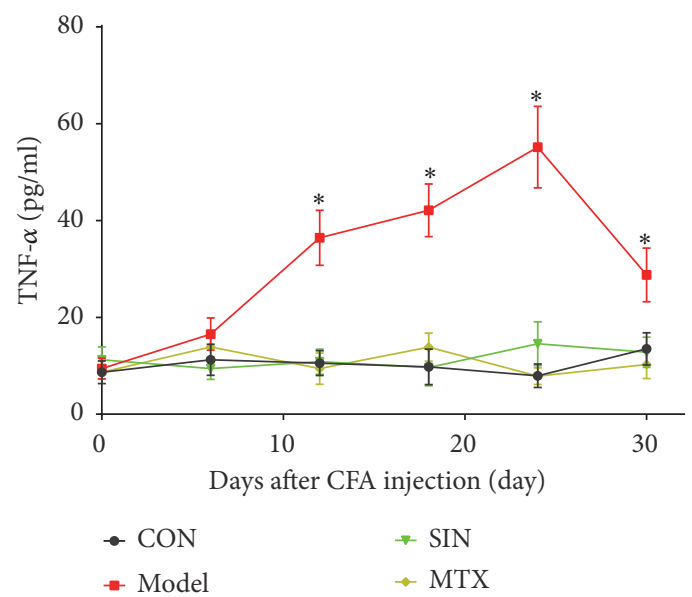

(d)

MTX

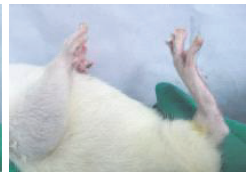

MTX

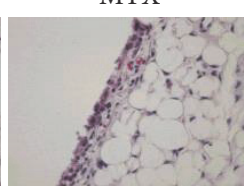

(f)

FIGURE 1: Effects of SIN on clinical progression in AIA rats from day 0 to 30. Rats were treated with SIN, MTX, or PBS once daily for 30 days after CFA administration. (a) Hind paw volume, (b) AI, (c) ESR, and (d) serum TNF- $\alpha$ concentration were measured on days 0, 6, 12, 18, 24 , and 30. Data are expressed as mean $\pm \mathrm{SD}(\mathrm{n}=8) . * \mathrm{P}<0.05$ versus the model group. (e) Clinical appearance of hind paws from the control or AIA rats treated with SIN, MTX, or PBS, on day 30 after CFA administration. (f) Marked lining layer hyperplasia in the synovium of the model group compared to the control, SIN, or MTX group in H\&E stained sections (400×).

$\alpha 7 \mathrm{nAChR}$ expression was significantly increased in the splenic lymphocytes of AIA rats compared with control rats. We used BCG to stimulate the proliferation and activation of splenic lymphocytes from AIA rats in vitro to study the relationships between $\alpha 7 \mathrm{nAChR}$ expression and lymphocyte activation. The proliferation of cells, expression of IFN$\gamma$ and IL-4, and protein level of pAKT were increased after BCG stimulation. However, SIN and MTX inhibited cell proliferation and decreased the expression of IFN- $\gamma$, IL-4, and the protein level of pAKT (Figures 5(b)-4(d)). 

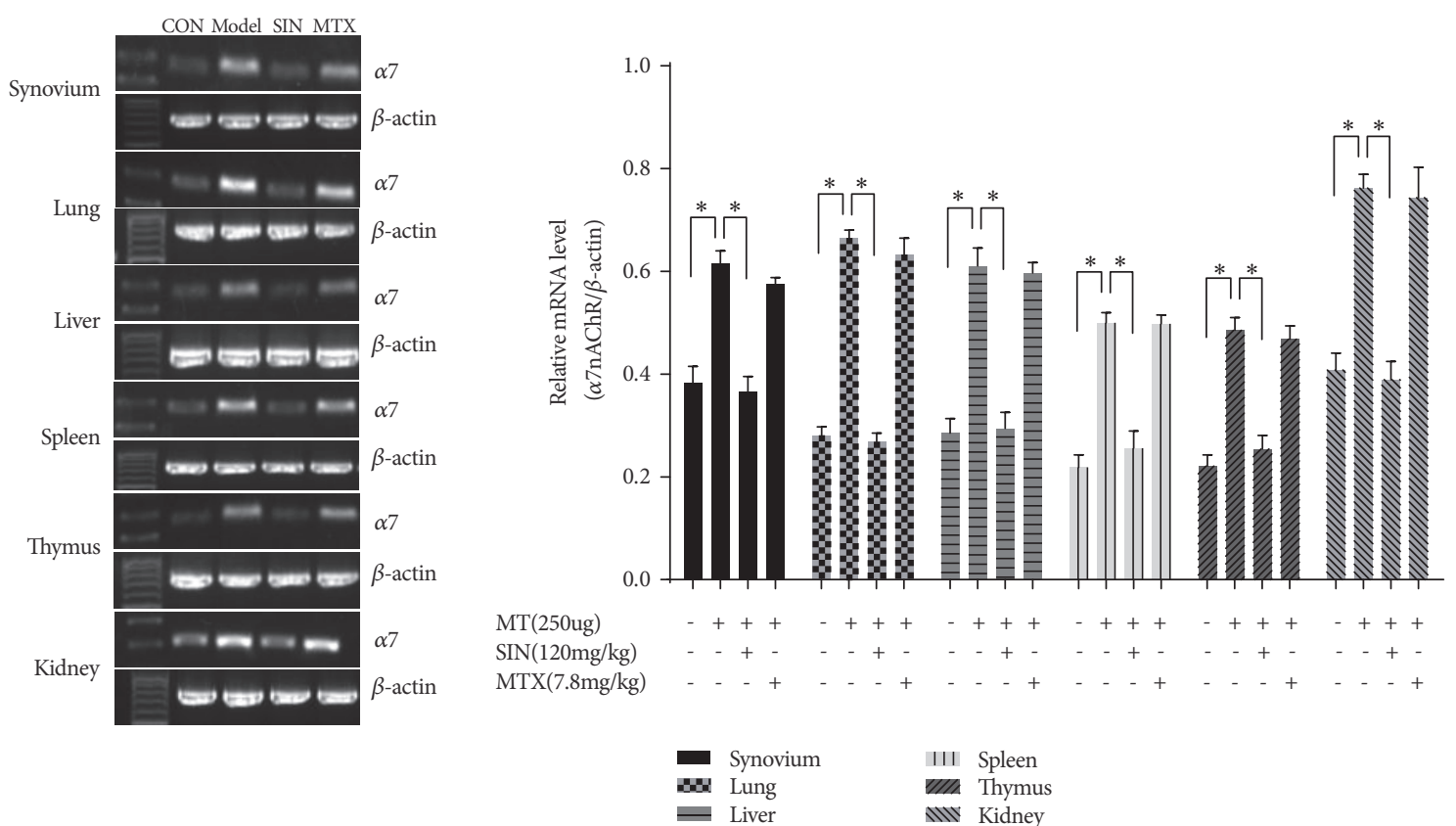

(a)

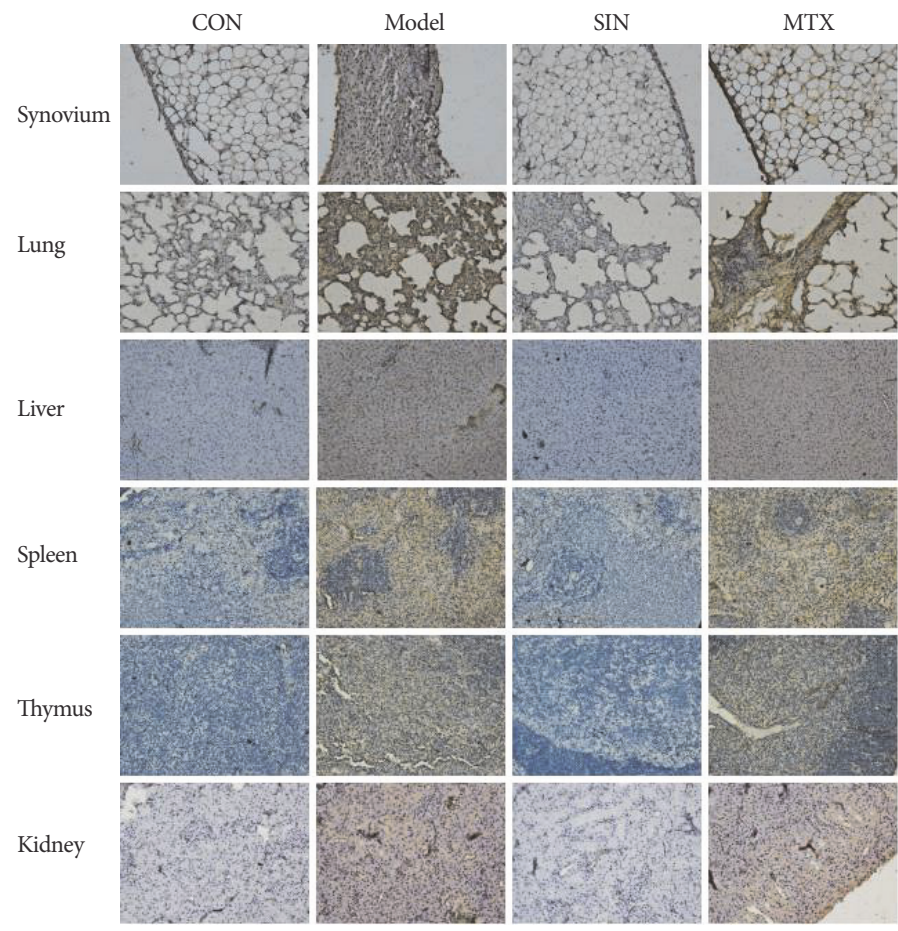

(b)

FiguRE 2: Effect of SIN on $\alpha 7 \mathrm{nAChR}$ expression in AIA rats on day 30. Shown are representative results of (a) $\alpha 7 \mathrm{nAChR}$ mRNA expression and (b) immunohistochemistry of $\alpha 7 \mathrm{nAChR}$ in synovium, lung, liver, spleen, thymus, and kidney (200×). Data are expressed as mean \pm SD $(\mathrm{n}=3) . * \mathrm{P}<0.05$ versus the model group.

Meanwhile, $\alpha 7 \mathrm{nAChR}$ expression in splenic lymphocytes was increased after BCG stimulation, and $\alpha 7 \mathrm{nAChR}$ expression was decreased by SIN (Figure 5(e)). However, MTX failed to decreased $\alpha 7 \mathrm{nAChR}$ expression in activated splenic lymphocytes.

\section{Discussion}

$\alpha 7 \mathrm{nAChR}$ has been identified as an essential player in the $\mathrm{CAP}$, in which acetylcholine (ACh) released by the vagal nerve interacts with $\alpha 7 \mathrm{nAChR}$ of nonneuronal cells such as 

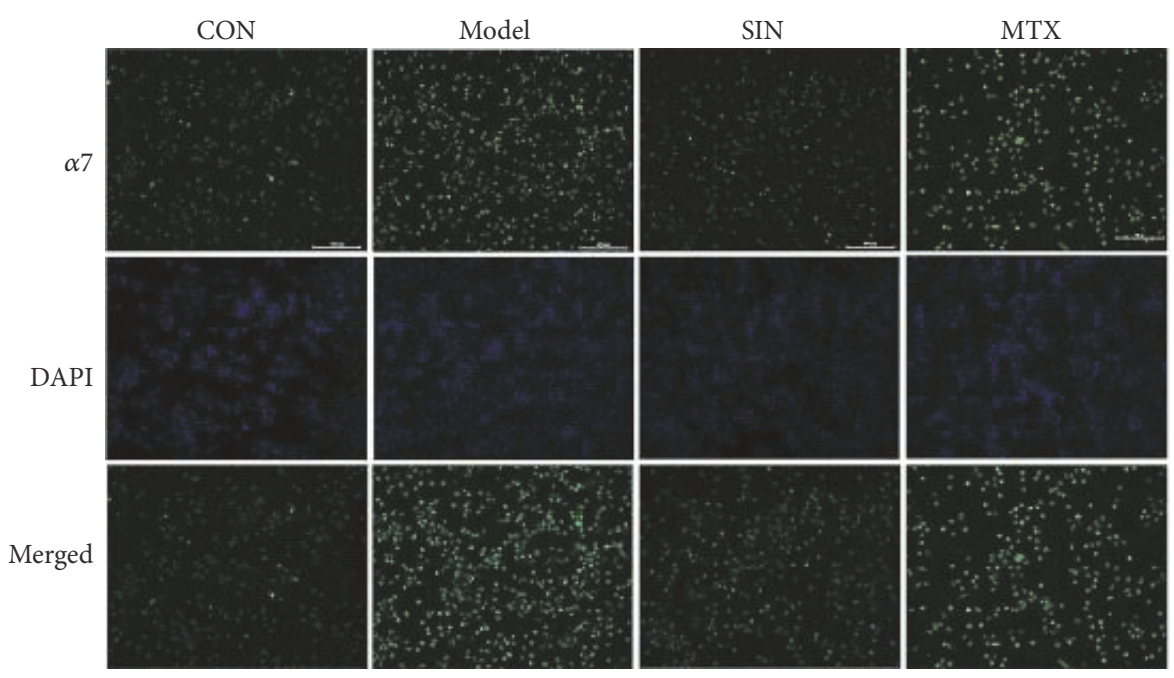

(a)
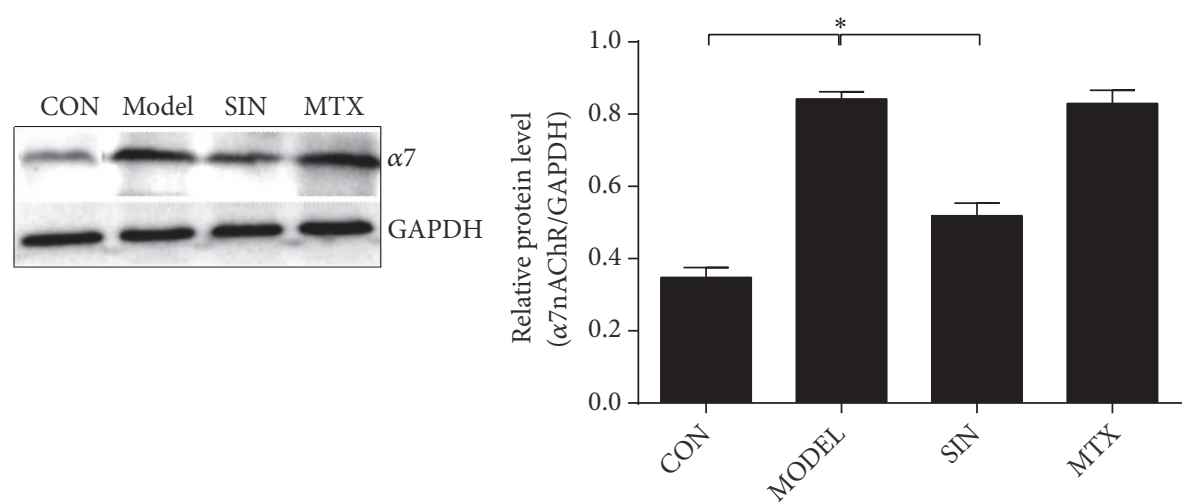

(b)

FIGURE 3: Effects of SIN on $\alpha 7 \mathrm{nAChR}$ expression in peritoneal macrophages and MLN on day 30. (a) Immunofluorescence with antibodies specific for $\alpha 7 \mathrm{nAChR}$ in peritoneal macrophages of control or AIA rats treated with SIN, MTX, or PBS (200×). (b) Protein expression of $\alpha 7 \mathrm{nAChR}$ detected by western blot in MLN. Data are expressed as mean $\pm \mathrm{SEM}(\mathrm{n}=3) . * \mathrm{P}<0.05$ versus the model group.

macrophages to reduce excessive inflammation $[16,17]$. Additionally, an anti-inflammatory effect of $\alpha 7 \mathrm{nAChR}$ activated by agonists such as nicotine was verified in innate immunity cells such as macrophages and in mice stimulated by LPS [1821]. Although it is well known that agonist-induced $\alpha 7 \mathrm{nAChR}$ activation inhibits the production of inflammatory cytokines in macrophages, a few studies also provided evidence that the presence or expression of $\alpha 7 \mathrm{nAChR}$ may be involved in pathological processes. For example, Guillermo reported that deletion of $\alpha 7 \mathrm{nAChR}$ decreased lesion size, macrophage content, and cell proliferation in advanced lesions in mice, suggesting a proatherogenic role for $\alpha 7 \mathrm{nAChR}$ in macrophages [22]. Inflammatory angiogenesis was markedly inhibited by inhibition of $\mathrm{nAChR}$ or deletion of $\alpha 7 \mathrm{nAChR}$ [23]. In addition, a marked expression of $\alpha 7 \mathrm{nAChR}$ was detected in the synovium of RA patients $[3,4]$.

In spite of these studies, the role of $\alpha 7 \mathrm{nAChR}$ in RA remains largely unknown. In CIA mice, increased incidence and severity of arthritis was detected in $\alpha 7 \mathrm{nAChR}^{-/-}$mice compared to wild-type mice; this aggravation of arthritis might be due to the lack of $\alpha 7 \mathrm{nAChR}$ and the resulting inability to respond to Ach [8]. On the contrary, a different study reported that a lack of $\alpha 7 \mathrm{nAChR}$ inhibited disease development in CIA mice, implying that $\alpha 7 \mathrm{nAChR}$ might be involved in adaptive immunity, and the alleviation of arthritis in $\alpha 7 \mathrm{nAChR}^{-/-}$mice might be related to a decreased proliferative immune response [9]. Another study showed that the severity and course of experimental autoimmune encephalomyelitis, a neuroinflammatory disease, was milder in $\alpha 7 \mathrm{nAChR}^{-/-}$mice than in wild-type mice. The lack of $\alpha 7 \mathrm{nAChR}$ affects the reactivity of immune cells in a complex way, and one possible reason is that the deficiency of $\alpha 7 \mathrm{nAChR}$ in antigen presenting cells reduces antigen presentation, implying a proinflammatory role for $\alpha 7 \mathrm{nAChR}$ [24]. Moreover, increased expression of $\alpha 7 \mathrm{nAChR}$ in human lymphocytes incubated with nicotine protected the lymphocytes from apoptosis [25]. Deletion of $\alpha 7 \mathrm{nAChR}$ in B lymphocytes resulted in apoptosis and decreased immune response in mice $[26,27]$. These previous studies suggest that the role of $\alpha 7 \mathrm{nAChR}$ cannot be simply anti-inflammatory, especially in adaptive immunity cells and in autoimmune diseases; the results of this present study support this idea. 

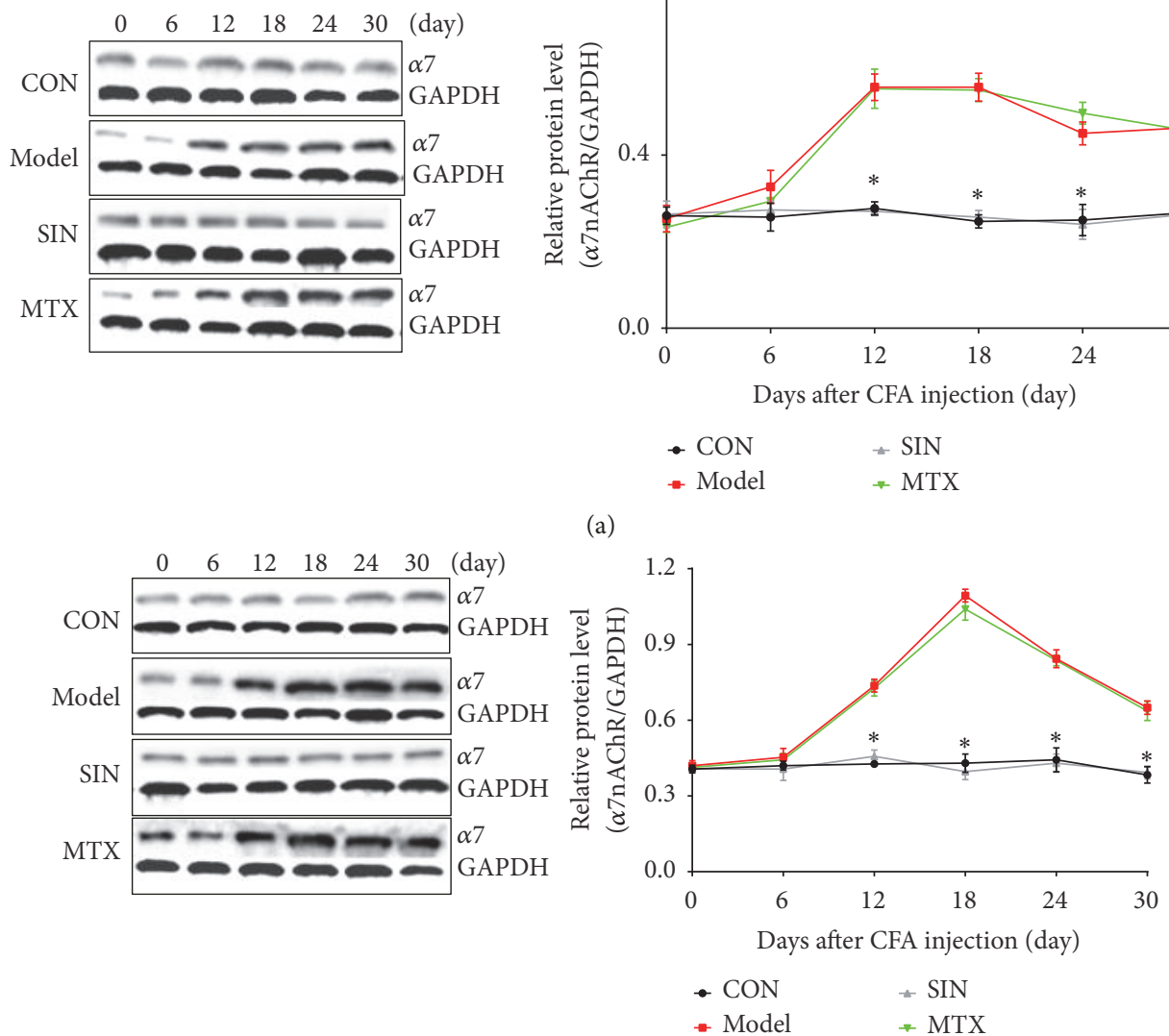

(b)
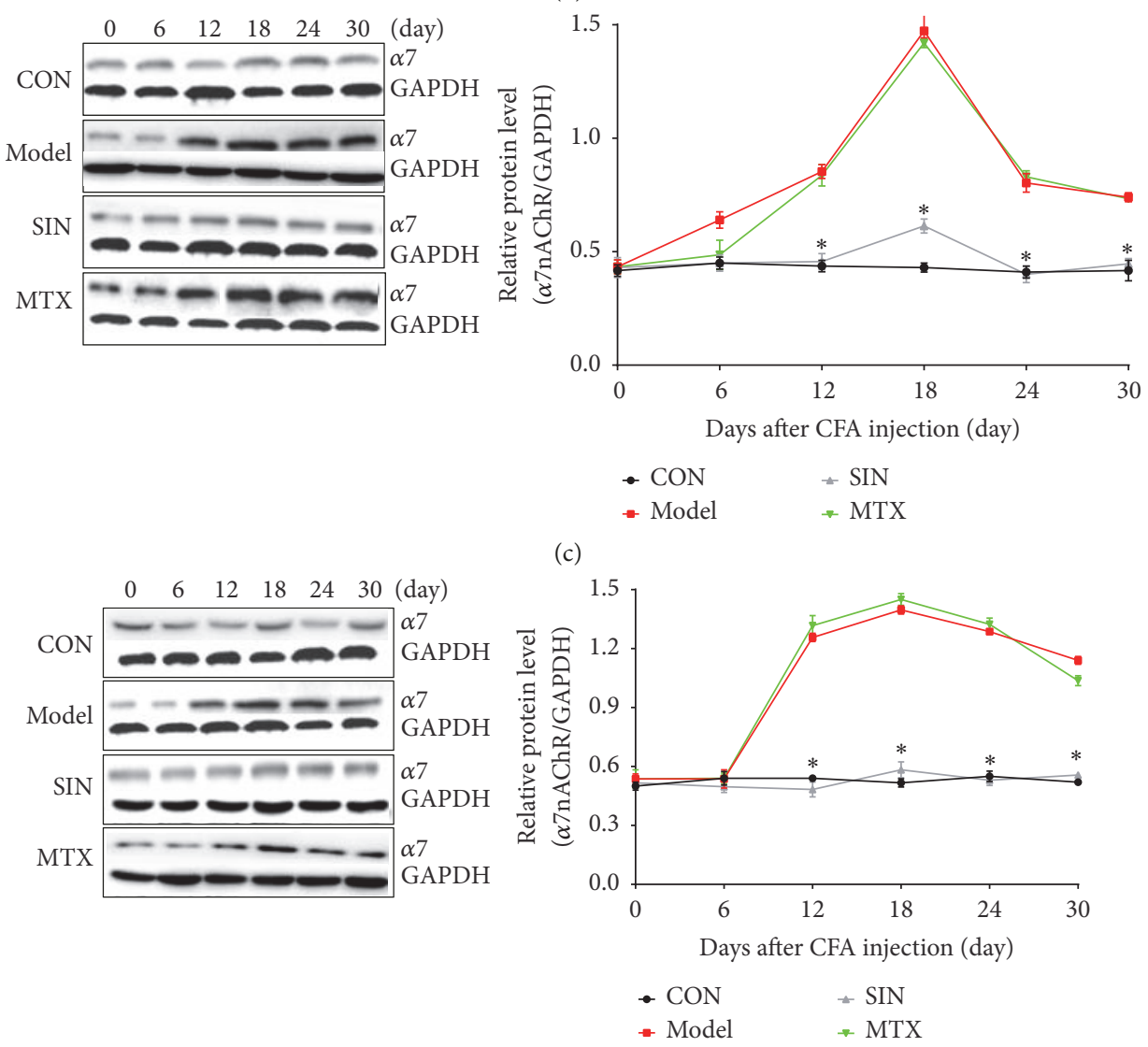

(d)

FIgURE 4: Continued. 

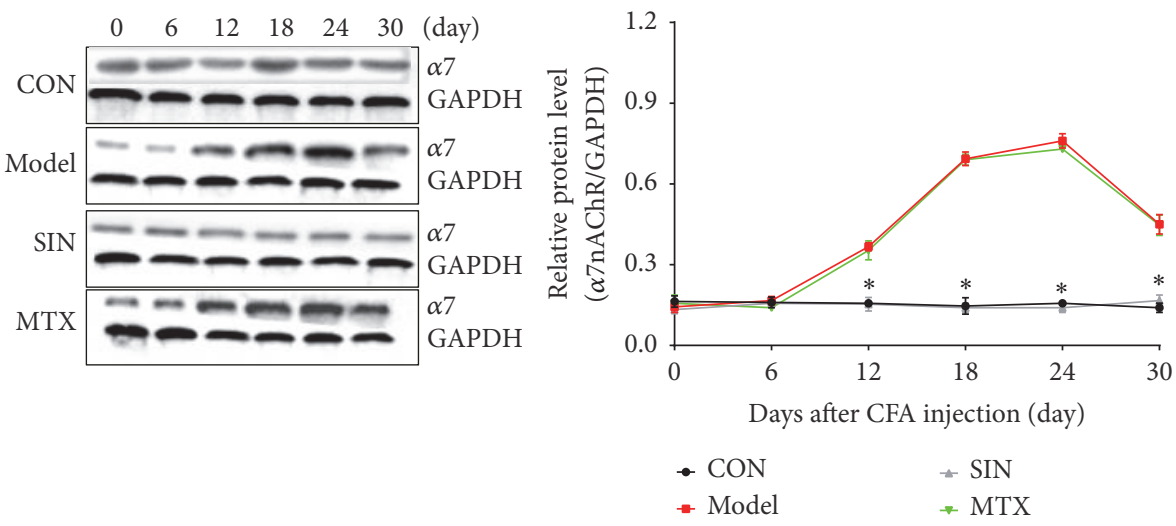

(e)
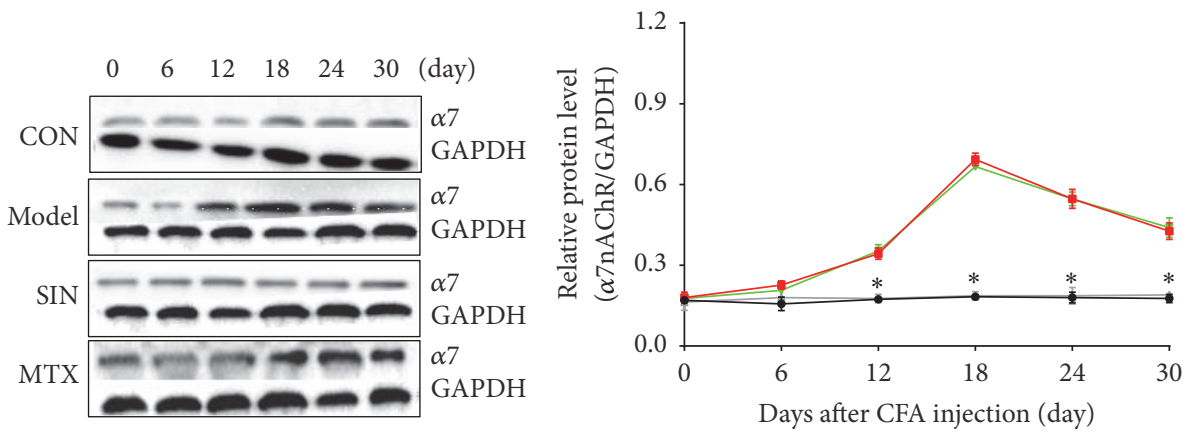

$$
\begin{array}{ll}
\text { - CON } & \rightarrow \text { SIN } \\
- \text { Model } & * \text { MTX }
\end{array}
$$

(f)
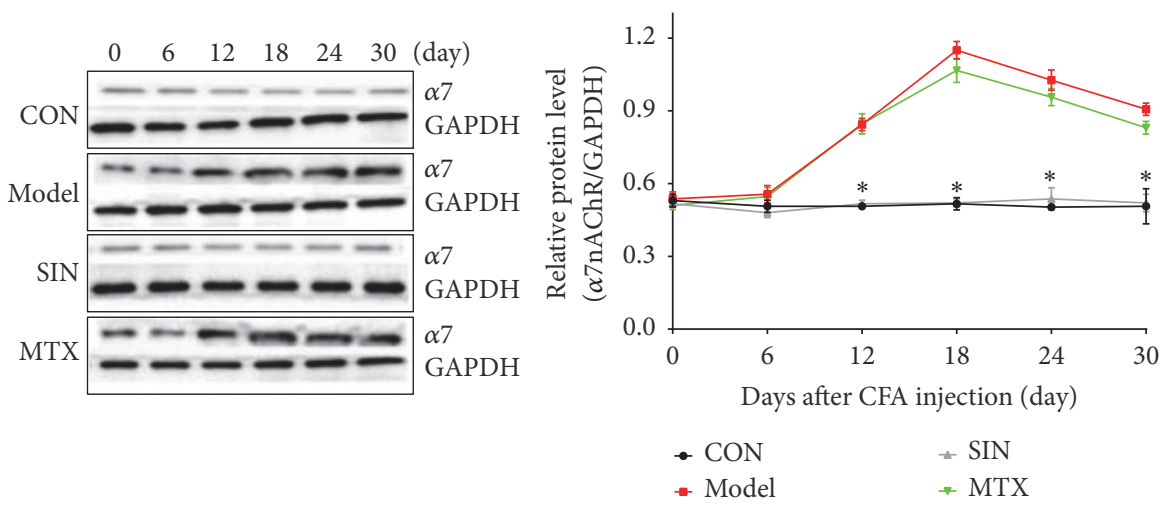

(g)

\begin{tabular}{ccccccccc}
\hline & & Synovium & Lung & Liver & Spleen & Thymus & Kidney & MLN \\
\hline Paw volume & $\mathrm{r}$ & $0.910 *$ & $0.955 *$ & $0.924 *$ & $0.900 *$ & $0.856 *$ & $0.947 *$ & $0.890 *$ \\
AI & $\mathrm{r}$ & $0.956 *$ & $0.924 *$ & $0.815 *$ & $0.991 *$ & $0.893 *$ & $0.910 *$ & $0.920 *$ \\
TNF- $\alpha$ & $\mathrm{r}$ & 0.804 & $0.839 *$ & 0.625 & $0.886 *$ & $0.944 *$ & $0.862 *$ & $0.948 *$ \\
ESR & $\mathrm{r}$ & 0.756 & 0.741 & 0.655 & $0.877 *$ & 0.607 & 0.604 & 0.654 \\
\hline
\end{tabular}

(h)

FIgURE 4: The time course of $\alpha 7 \mathrm{nAChR}$ expression and correlation analysis with clinical progression in AIA rats. ((a)-(g)) The expression of $\alpha 7 \mathrm{nAChR}$ protein detected by western blot in the synovium, lung, liver, spleen, thymus, kidney, and MLN of AIA rats on days $0,6,12,18,24$, and 30. Data are expressed as mean $\pm \operatorname{SEM}(\mathrm{n}=3) . * \mathrm{P}<0.05$ versus the model group. (h) The correlation analysis between $\alpha 7 \mathrm{nAChR}$ expression and clinical progression, including hind paw volume, AI, serum TNF- $\alpha$ concentration, and ESR. $* \mathrm{P}<0.05$ indicates statistical significance, $r=0.8-1.0$ indicates very strong correlation, $r=0.6-0.8$ indicates strong correlation, $r=0.4-0.6$ indicates moderate correlation, $r=0.2-0.4$ indicates weak correlation, and $\mathrm{r}=0.0-0.2$ indicates very weak or no correlation. 

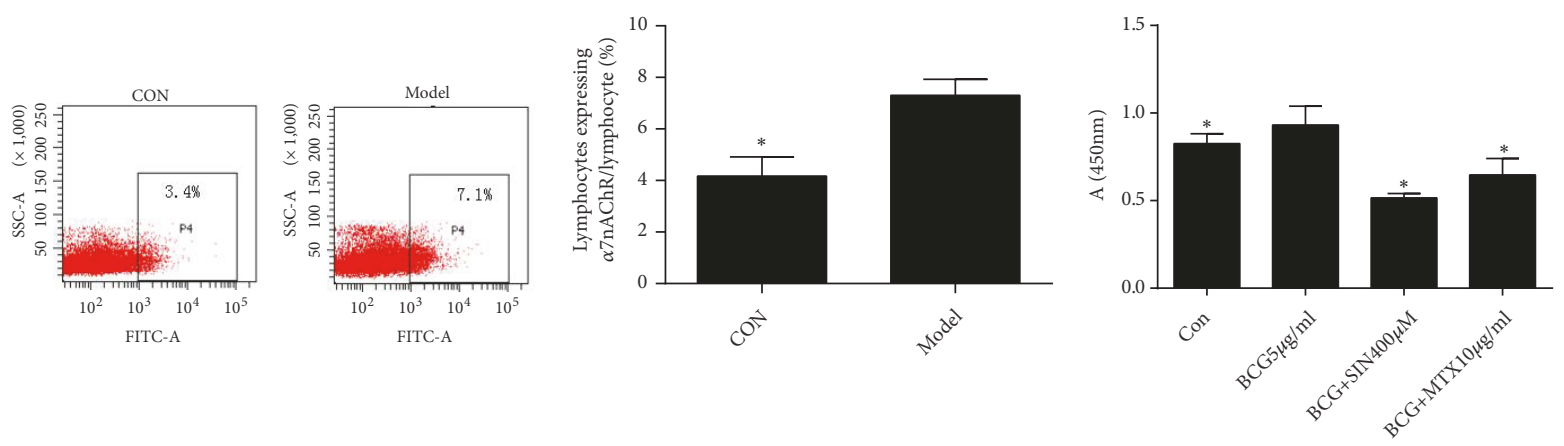

(a)

(b)

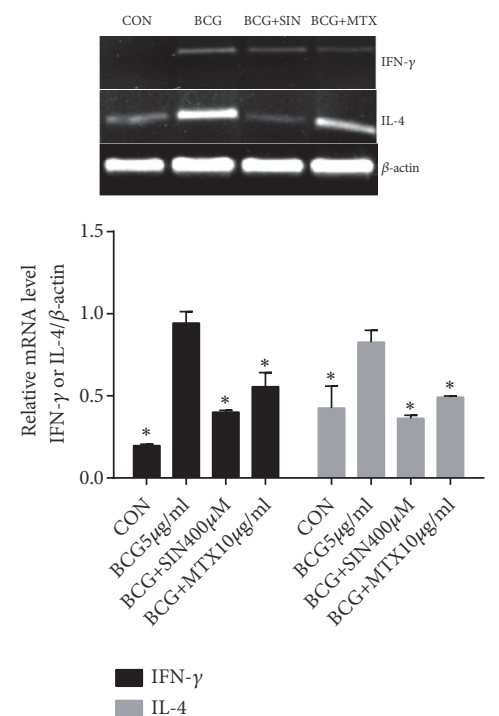

(c)

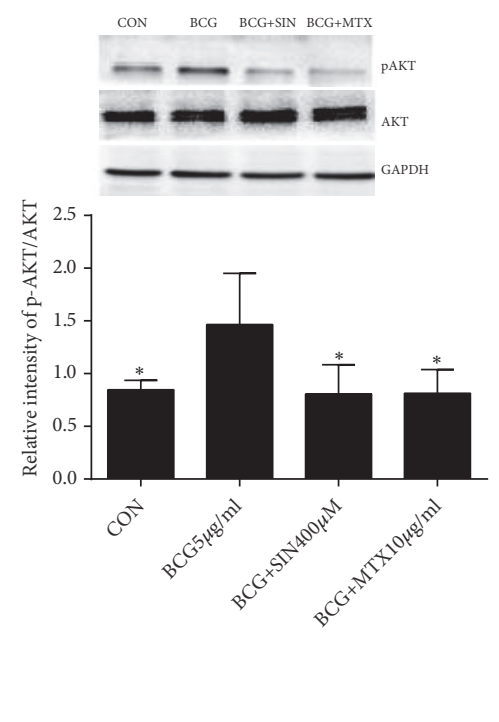

(d)

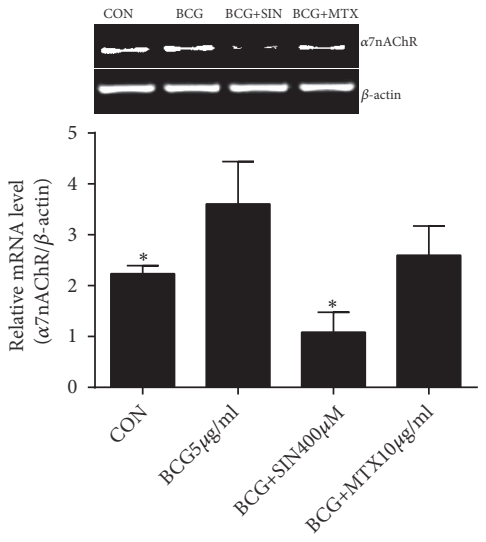

(e)

FIGURE 5: Effect of SIN on activated lymphocytes and $\alpha 7 \mathrm{nAChR}$ expression. (a) Lymphocytes expressing $\alpha 7 \mathrm{nAChR}$ in control or AIA rats were measured by flow cytometry $(n=3)$. (b) Lymphocyte proliferation was detected by the CCK8 assay $(n=5)$. mRNA expression of $(c)$ IFN- $\gamma$, IL- 4 and (e) $\alpha 7 \mathrm{nAChR}$ was detected by RT-PCR and (d) protein expression of pAKT and AKT was detected by western blot in lymphocytes $(\mathrm{n}=3)$. Data are expressed as mean \pm SEM. $* \mathrm{P}<0.05$ versus the model or $\mathrm{BCG}$ group.

We studied the relationship between $\alpha 7 \mathrm{nAChR}$ expression and the clinical progression of RA for the first time in AIA rats. We found an elevation of $\alpha 7 \mathrm{nAChR}$ expression in tissues, peritoneal macrophages, and splenic lymphocytes of AIA rats, which was consistent with previous observations of $\alpha 7 \mathrm{nAChR}$ expression in the synovium and fibroblast-like synoviocytes of RA patients [3, 4]. SIN exerted its antiinflammatory action by ameliorating the clinical signs of RA, such as hind paw volume, AI, serum TNF- $\alpha$ concentration, ESR, and pathological changes of the synovium. In addition, SIN reduced $\alpha 7 \mathrm{nAChR}$ expression in tissues and cells. On the other hand, MTX had no significant effect on $\alpha 7 \mathrm{nAChR}$ expression, although it had a dramatic anti-inflammatory effect. Taken together, our results indicate that SIN plays an antiarthritic role accompanied with reduction of $\alpha 7 \mathrm{nAChR}$ expression, which is different from the mechanism of action of MTX.

Furthermore, to investigate the relationship between $\alpha 7 \mathrm{nAChR}$ expression and clinical progression of RA, we observed the time course of $\alpha 7 \mathrm{nAChR}$ protein levels in various tissues of AIA rats on days $0,6,12,18,24$, and 30 . Our findings suggest that the pathogenesis and severity of RA are correlated with the elevation of $\alpha 7 \mathrm{nAChR}$ expression. The correlation analysis between $\alpha 7 \mathrm{nAChR}$ expression and the four clinical signs revealed a very strong correlation between hind paw swelling and AI and the $\alpha 7 \mathrm{nAChR}$ level in the synovium, lung, liver, spleen, thymus, kidney, and MLN. A very strong correlation between serum TNF- $\alpha$ concentration and $\alpha 7 \mathrm{nAChR}$ expression in lung, spleen, thymus, kidney, and MLN was also observed. These results suggest that $\alpha 7 \mathrm{nAChR}$ might be involved in the occurrence and development of RA.

We isolated spleen lymphocytes to investigate whether $\alpha 7 \mathrm{nAChR}$ is involved in lymphocyte activation in vitro. IFN$\gamma$ and IL- 4 are produced by T cells and play an important role in their proliferation and differentiation [28]. Downstream target proteins during chemotherapy or radiotherapy such as caspase- $9, \mathrm{Bad}$, and NF- $\kappa \mathrm{B}$ are regulated by activated AKT, which promotes cell proliferation and angiogenesis and inhibits apoptosis [29-32]. Phosphorylation of AKT can 
cause cell proliferation and antiapoptosis [33]. We found that, upon stimulation with BCG, the splenic lymphocytes of AIA rats proliferated significantly, and mRNA levels of IFN- $\gamma$ and IL- 4 and the protein level of p-AKT were increased. In addition, $\alpha 7 \mathrm{nAChR}$ expression was increased in BCG-activated lymphocytes. While both SIN and MTX inhibited cell proliferation and phosphorylation of AKT and reduced IFN- $\gamma$ and IL- 4 , only SIN downregulated $\alpha 7 \mathrm{nAChR}$ expression. These data suggest that $\alpha 7 \mathrm{nAChR}$ is involved in the activation of lymphocytes and is perhaps a target for SIN inhibiting the activation of lymphocytes.

\section{Conclusions}

In conclusion, the expression of $\alpha 7 \mathrm{nAChR}$ increases when RA begins to develop, and $\alpha 7 \mathrm{nAChR}$ has a positive correlation with the clinical progression of RA and lymphocyte activation in AIA rats. These findings indicate that $\alpha 7 \mathrm{nAChR}$ may be a novel target for RA treatment. The antiarthritic effects of SIN were associated with diminished $\alpha 7 \mathrm{nAChR}$ expression, whereas MTX had no significant impact on $\alpha 7 \mathrm{nAChR}$ expression, indicating that the antiarthritic mechanism of SIN is different from MTX. Our results suggest that inhibition of $\alpha 7 \mathrm{nAChR}$ expression by SIN might be an important supplement to the treatment strategy for RA. Further studies are required to elucidate the precise mechanisms underlying the involvement of $\alpha 7 \mathrm{nAChR}$ in RA.

\section{Abbreviations}

$\begin{array}{ll}\text { AI: } & \text { Arthritic index } \\ \text { AIA: } & \text { Adjuvant-induced arthritis } \\ \alpha 7 n A C h R: & \text { Alpha7 nicotinic acetylcholine receptor } \\ \text { BCG: } & \text { Bacille Calmette Guerin } \\ \text { CAP: } & \text { Cholinergic anti-inflammatory pathway } \\ \text { CFA: } & \text { Complete Freund's adjuvant } \\ \text { ESR: } & \text { Erythrocyte sedimentation rate } \\ \text { MLN: } & \text { Mesenteric lymph node } \\ \text { MTX: } & \text { Methotrexate } \\ \text { RA: } & \text { Rheumatoid arthritis } \\ \text { SIN: } & \text { Sinomenine. }\end{array}$

\section{Data Availability}

The data used to support the findings of this study are available from the corresponding author upon request.

\section{Conflicts of Interest}

The authors declare that they have no conflicts of interest.

\section{Acknowledgments}

This work was supported by the National Natural Science Foundation of China (81573672), the Joint Research Fund for Overseas Chinese Scholars and Scholars in Hong Kong and Macao of National Natural Science Fund of China (81628016), and the open project of the State Key Laboratory of Quality Research in Chinese Medicine (Macau University of Science and Technology, MUST-SKL-2016-03) funded by the Macao Science and Technology Development Fund, Macau Special Administrative Region.

\section{References}

[1] X. Cai, H. Zhou, F. W. Yuen et al., "Suppressive effects of QFGJS, a preparation from an anti-arthritic herbal formula, on rat experimental adjuvant-induced arthritis," Biochemical and Biophysical Research Communications, vol. 337, no. 2, pp. 586594, 2005.

[2] J. S. Smolen, D. Aletaha, and I. B. McInnes, "Rheumatoid arthritis," The Lancet, vol. 388, no. 10055, pp. 2023-2038, 2016.

[3] M. A. Van Maanen, S. P. Stoof, E. P. Van Der Zanden et al., "The $\alpha 7$ nicotinic acetylcholine receptor on fibroblast-like synoviocytes and in synovial tissue from rheumatoid arthritis patients: A possible role for a key neurotransmitter in synovial inflammation," Arthritis \& Rheumatology, vol. 60, no. 5, pp. 1272-1281, 2009.

[4] S. Forsgren, "Presence of ChAT mRNA and a very marked $\alpha 7 \mathrm{nAChR}$ immunoreaction in the synovial lining layer of the knee joint," Life Sciences, vol. 91, no. 21-22, pp. 1043-1047, 2012.

[5] Y. Liu, H. Lin, R. Zou et al., "Suppression of complete freund's adjuvant-induced adjuvant arthritis by cobratoxin," Acta Pharmacologica Sinica, vol. 30, no. 2, pp. 219-227, 2009.

[6] H. Wang, H. Liao, M. Ochani et al., "Cholinergic agonists inhibit HMGB1 release and improve survival in experimental sepsis," Nature Medicine, vol. 10, no. 11, pp. 1216-1221, 2004.

[7] M. Cortes, M. Cao, H. L. Liu et al., “ $\alpha 7$ nicotinic acetylcholine receptor signaling modulates the inflammatory phenotype of fetal brain microglia: first evidence of interference by iron homeostasis," Scientific Reports, vol. 7, no. 1, p. 10645, 2017.

[8] M. A. van Maanen, S. P. Stoof, G. J. LaRosa, M. J. Vervoordeldonk, and P. P. Tak, "Role of the cholinergic nervous system in rheumatoid arthritis: aggravation of arthritis in nicotinic acetylcholine receptor $\alpha 7$ subunit gene knockout mice," Annals of the Rheumatic Diseases, vol. 69, no. 9, pp. 1717-1723, 2010.

[9] M. Westman, S. Saha, M. Morshed, and J. Lampa, "Lack of acetylcholine nicotine alpha 7 receptor suppresses development of collagen-induced arthritis and adaptive immunity," Clinical \& Experimental Immunology, vol. 162, no. 1, pp. 62-67, 2010.

[10] Y. Wang, Y. Fang, W. Huang et al., "Effect of sinomenine on cytokine expression of macrophages and synoviocytes in adjuvant arthritis rats," Journal of Ethnopharmacology, vol. 98, no. 1-2, pp. 37-43, 2005.

[11] H. Zhou, Y. F. Wong, J. Wang, X. Cai, and L. Liu, "Sinomenine ameliorates arthritis via MMPs, TIMPs, and cytokines in rats," Biochemical and Biophysical Research Communications, vol. 376, no. 2, pp. 352-357, 2008.

[12] L. Yi, J. Luo, B. Xie et al., " $\alpha 7$ nicotinic acetylcholine receptor is a novel mediator of sinomenine anti-inflammation effect in macrophages stimulated by lipopolysaccharide," Shock, vol. 44, no. 2, pp. 188-195, 2015.

[13] X. Cai, Y. F. Wong, H. Zhou et al., "Manipulation of the induction of adjuvant arthritis in Sprague-Dawley rats," Inflammation Research, vol. 55, no. 9, pp. 368-377, 2006.

[14] W. Van Eden, J. Wagenaar-Hilbers, and M. Wauben, "Animal models for autoimmune and inflammatory disease: adjuvant arthritis in the rat," in Current Protocols in Immunology, pp. 1-11, Wiley, New York, NY, USA, 1994. 
[15] C. Liu, M.-S. Zhou, Y. Li et al., "Oral nicotine aggravates endothelial dysfunction and vascular inflammation in dietinduced obese rats: Role of macrophage TNF $\alpha$," Plos One, vol. 12, no. 12, Article ID e0188439, 2017.

[16] W. J. de Jonge, E. P. van der Zanden, F. O. The et al., "Stimulation of the vagus nerve attenuates macrophage activation by activating the Jak2-STAT3 signaling pathway," Nature Immunology, vol. 6, no. 8, pp. 844-851, 2005.

[17] L. C. Gahring and S. W. Rogers, "Neuronal nicotinic acetylcholine receptor expression and function on nonneuronal cells," The AAPS Journal, vol. 7, no. 4, pp. E885-E894, 2005.

[18] H. Yoshikawa, M. Kurokawa, N. Ozaki et al., "Nicotine inhibits the production of proinflammatory mediators in human monocytes by suppression of I- $\kappa \mathrm{B}$ phosphorylation and nuclear factor- $\kappa \mathrm{B}$ transcriptional activity through nicotinic acetylcholine receptor $\alpha 7$," Clinical \& Experimental Immunology, vol. 146, no. 1, pp. 116-123, 2006.

[19] W.-Y. Cui and M. D. Li, "Nicotinic modulation of innate immune pathways via $\alpha 7$ nicotinic acetylcholine receptor," Journal of Neuroimmune Pharmacology, vol. 5, no. 4, pp. 479488, 2010.

[20] C. A. Báez-Pagán, M. Delgado-Vélez, and J. A. LasaldeDominicci, "Activation of the Macrophage $\alpha 7$ Nicotinic Acetylcholine Receptor and Control of Inflammation," Journal of Neuroimmune Pharmacology, vol. 10, no. 3, pp. 468-476, 2015.

[21] K. Tsoyi, H. J. Jang, J. W. Kim et al., "Stimulation of Alpha7 nicotinic acetylcholine receptor by nicotine attenuates inflammatory response in macrophages and improves survival in experimental model of sepsis through heme oxygenase-1 induction," Antioxidants \& Redox Signaling, vol. 14, no. 11, pp. 20572070, 2011.

[22] R. H. Lee and G. Vazquez, "Reduced size and macrophage content of advanced atherosclerotic lesions in mice with bone marrow specific deficiency of alpha 7 nicotinic acetylcholine receptor," Plos One, vol. 10, no. 3, Article ID e0124584, 2015.

[23] C. Heeschen, M. Weis, A. Aicher, S. Dimmeler, and J. P. Cooke, "A novel angiogenic pathway mediated by non-neuronal nicotinic acetylcholine receptors," The Journal of Clinical Investigation, vol. 110, no. 4, pp. 527-536, 2002.

[24] E. Nizri, M. Irony-Tur-Sinai, O. Lory, A. Orr-Urtreger, E. Lavi, and T. Brenner, "Activation of the cholinergic antiinflammatory system by nicotine attenuates neuroinflammation via suppression of Th1 and Th17 responses," The Journal of Immunology, vol. 183, no. 10, pp. 6681-6688, 2009.

[25] M. J. De Rosa, M. d. Esandi, A. Garelli, D. Rayes, and C. Bouzat, "Relationship between $\alpha 7 \mathrm{nAChR}$ and apoptosis in human lymphocytes," Journal of Neuroimmunology, vol. 160, no. 1-2, pp. 154-161, 2005.

[26] M. Skok, R. Grailhe, and J.-P. Changeux, "Nicotinic receptors regulate B lymphocyte activation and immune response," European Journal of Pharmacology, vol. 517, no. 3, pp. 246-251, 2005.

[27] M. Skok, R. Grailhe, F. Agenes, and J.-P. Changeux, "The role of nicotinic acetylcholine receptors in lymphocyte development," Journal of Neuroimmunology, vol. 171, no. 1-2, pp. 86-98, 2006.

[28] V. Khatri, N. Chauhan, K. Vishnoi, A. von Gegerfelt, C. Gittens, and R. Kalyanasundaram, "Prospects of developing a prophylactic vaccine against human lymphatic filariasis-evaluation of protection in non-human primates," International Journal for Parasitology, 2018.

[29] W. Shao, J. D. Growney, Y. Feng et al., "Activity of deacetylase inhibitor panobinostat (LBH589) in cutaneous T-cell lymphoma models: Defining molecular mechanisms of resistance,"
International Journal of Cancer, vol. 127, no. 9, pp. 2199-2208, 2010.

[30] X. Yang, M. Fraser, U. M. Moll, A. Basak, and B. K. Tsang, "Aktmediated cisplatin resistance in ovarian cancer: modulation of p53 action on caspase-dependent mitochondrial death pathway," Cancer Research, vol. 66, no. 6, pp. 3126-3136, 2006.

[31] I. Vivanco and C. L. Sawyers, "The phosphatidylinositol 3kinase-AKT pathway in human cancer," Nature Reviews Cancer, vol. 2, no. 7, pp. 489-501, 2002.

[32] M. Fraser, B. M. Leung, X. Yan, H. C. Dan, J. Q. Cheng, and B. K. Tsang, "p53 is a determinant of X-linked inhibitor of apoptosis protein/Akt-mediated chemoresistance in human ovarian cancer cells," Cancer Research, vol. 63, no. 21, pp. 70817088, 2003.

[33] Q. Cai, H. Huang, D. Qian et al., "13-methyltetradecanoic acid exhibits anti-tumor activity on t-cell lymphomas in vitro and in vivo by down-regulating $\mathrm{p}$-akt and activating caspase-3," Plos One, vol. 8, no. 6, Article ID e65308, 2013. 


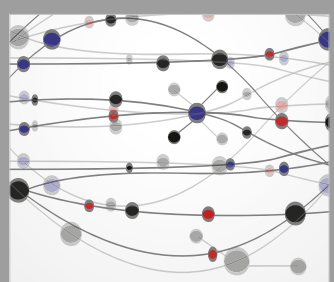

The Scientific World Journal
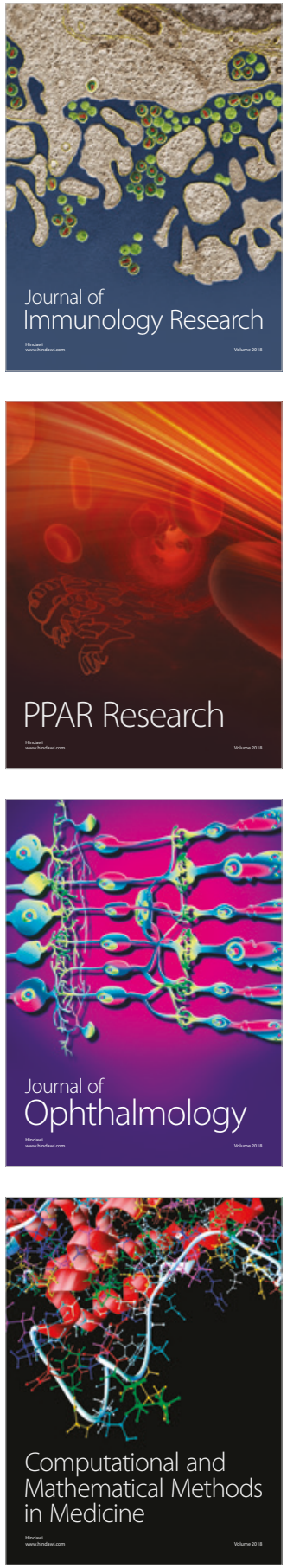

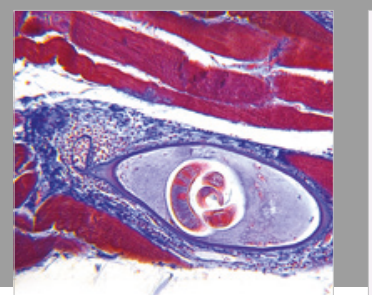

Gastroenterology Research and Practice

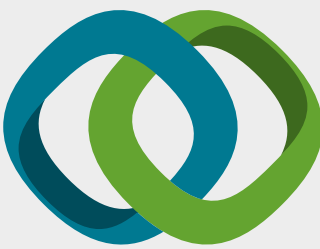

\section{Hindawi}

Submit your manuscripts at

www.hindawi.com
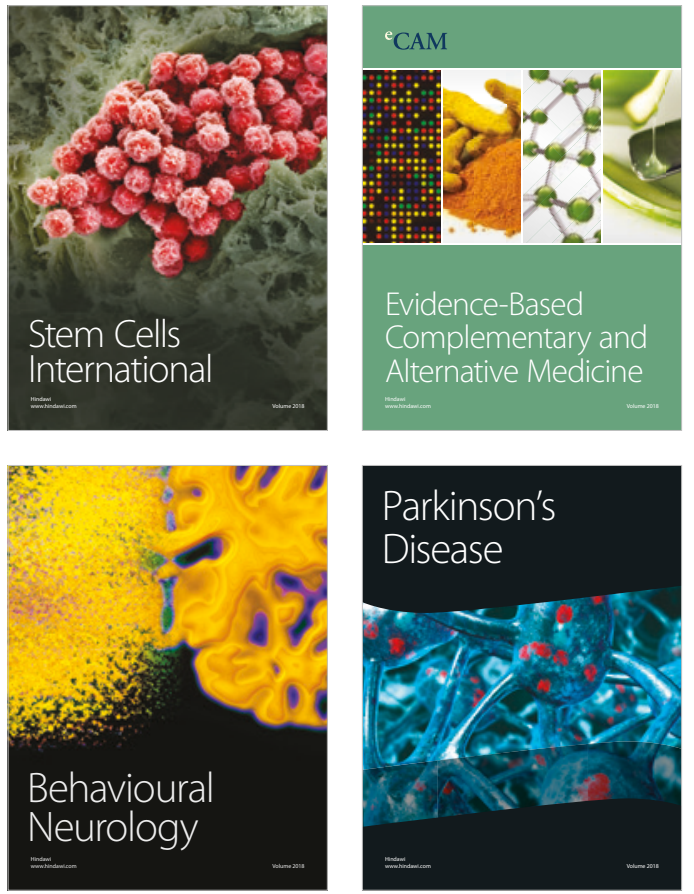

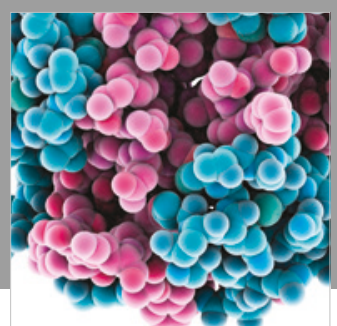

ournal of

Diabetes Research

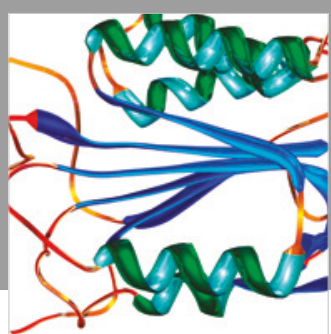

Disease Markers
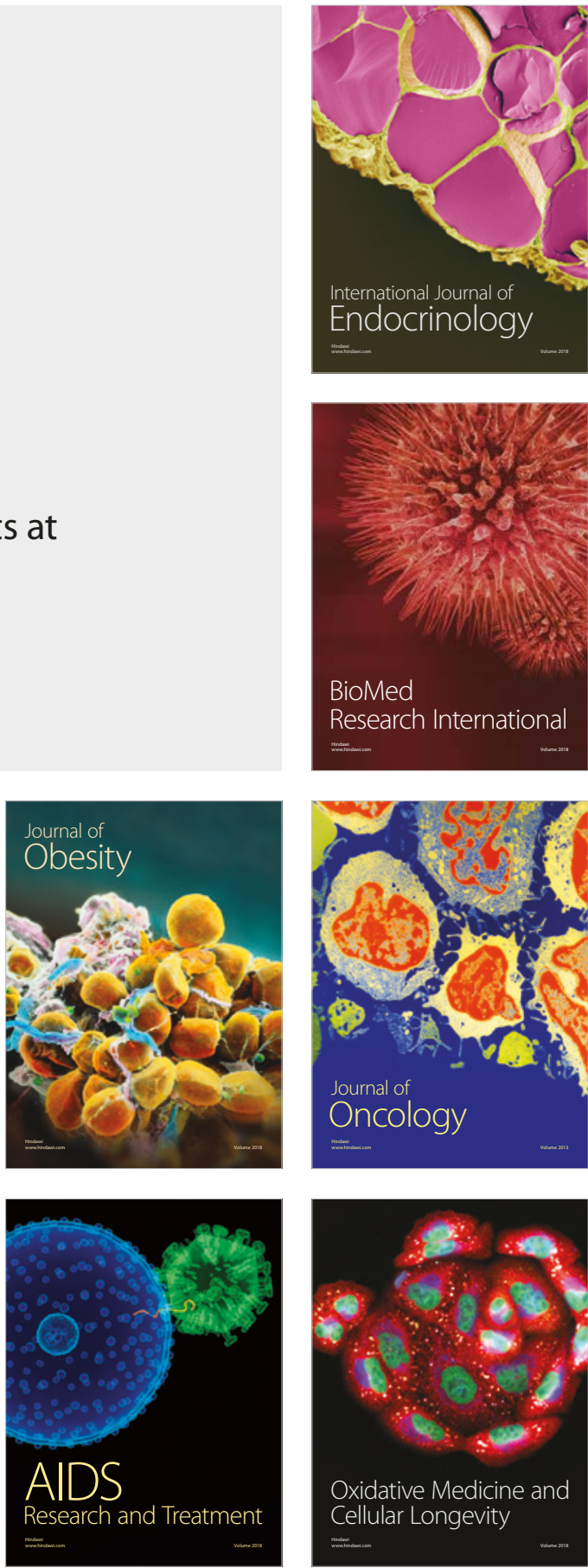